\title{
Video Article \\ Detection of Foodborne Bacterial Pathogens from Individual Filth Flies
}

\author{
Monica Pava-Ripoll ${ }^{1}$, Rachel E.G. Pearson ${ }^{1}$, Amy K. Miller ${ }^{1}$, George C. Ziobro ${ }^{1}$ \\ ${ }^{1}$ Center for Food Safety and Applied Nutrition, U.S. Food and Drug Administration
}

Correspondence to: Monica Pava-Ripoll at Monica.Pava-Ripoll@fda.hhs.gov

URL: https://www.jove.com/video/52372

DOI: doi:10.3791/52372

Keywords: Environmental Sciences, Issue 96, Synanthropy, filth flies, Cronobacter, Listeria monocytogenes, Salmonella, Escherichia coli O157:H7, shiga-toxigenic E. coli, STEC, PCR-based methods, foodborne illness, foodborne outbreak investigations.

Date Published: 2/13/2015

Citation: Pava-Ripoll, M., Pearson, R.E., Miller, A.K., Ziobro, G.C. Detection of Foodborne Bacterial Pathogens from Individual Filth Flies. J. Vis. Exp. (96), e52372, doi:10.3791/52372 (2015).

\section{Abstract}

There is unanimous consensus that insects are important vectors of foodborne pathogens. However, linking insects as vectors of the pathogen causing a particular foodborne illness outbreak has been challenging. This is because insects are not being aseptically collected as part of an environmental sampling program during foodborne outbreak investigations and because there is not a standardized method to detect foodborne bacteria from individual insects. To take a step towards solving this problem, we adapted a protocol from a commercially available PCR-based system that detects foodborne pathogens from food and environmental samples, to detect foodborne pathogens from individual flies.Using this standardized protocol, we surveyed 100 wild-caught flies for the presence of Cronobacter spp., Salmonella enterica, and Listeria monocytogenes and demonstrated that it was possible to detect and further isolate these pathogens from the body surface and the alimentary canal of a single fly. Twenty-two percent of the alimentary canals and $8 \%$ of the body surfaces from collected wild flies were positive for at least one of the three foodborne pathogens. The prevalence of Cronobacter spp. on either body part of the flies was statistically higher (19\%) than the prevalence of S. enterica $(7 \%)$ and L.monocytogenes (4\%). No false positives were observed when detecting $S$. enterica and L. monocytogenes using this PCR-based system because pure bacterial cultures were obtained from all PCR-positive results. However, pure Cronobacter colonies were not obtained from about $50 \%$ of PCR-positive samples, suggesting that the PCR-based detection system for this pathogen cross-reacts with other Enterobacteriaceae present among the highly complex microbiota carried by wild flies. The standardized protocol presented here will allow laboratories to detect bacterial foodborne pathogens from aseptically collected insects, thereby giving public health officials another line of evidence to find out how the food was contaminated when performing foodborne outbreak investigations.

Video Link

The video component of this article can be found at https://www.jove.com/video/52372/

\section{Introduction}

Insects play an important role in the transmission of food-related diseases because they can spread pathogens to food or food contact surfaces and utensils ${ }^{1}$. Among insects, flies, cockroaches, and ants exhibit behaviors that favor the spread of foodborne pathogens. These behaviors include an association with decaying matter, refuse and feces, endophily (entering buildings), and synanthropy (cohabiting with humans) ${ }^{2}$. Foodborne pathogens such as Salmonella spp., Listeria monocytogenes, Campylobacter spp., Escherichia coli O157:H7, and members of the genus Cronobacter (formerly Enterobacter sakazakii) have been reported to be transmitted by insects ${ }^{3-5}$. Synanthropic filth flies mechanically spread foodborne bacteria by transferring pathogens from their contaminated body surfaces. However, the presence of foodborne pathogens in the alimentary canal of flies can be up to three times greater than that observed on their body surfaces (body, head, legs, and wings) ${ }^{5}$. Foodborne pathogens can also remain in the fly's alimentary canal for a greater length of time than on the body surface ${ }^{6,7}$ and in some instances, they are able to multiply, colonizing the fly's digestive tract ${ }^{4,8,9}$. This increases the vector potential of flies because they can further spread foodborne pathogens through defecation and regurgitation ${ }^{10,11}$.

Nowadays, there are improved surveillance systems that are able to detect foodborne illness outbreaks more rapidly. While performing foodborne outbreak investigations, public health officials look for the food that may be the source(s) or vehicle(s) of infection. Investigators may also perform an environmental assessment of the facility (or facilities) involved to find out how the food was contaminated and may collect samples as part of the investigation ${ }^{12}$. Despite the vast amount of scientific literature concerning insects as carriers of foodborne pathogens, linking insects as vectors of the pathogen causing a particular foodborne illness outbreak has been challenging. This is mainly because insects are not being aseptically collected as part of environmental sampling programs during foodborne outbreak investigations. To include insects, particularly those that exhibit behaviors that favor the spread of foodborne pathogens, as part of an environmental sampling procedure, a standardized, rapid, sensitive and reliable protocol to detect foodborne pathogens from a single insect needs to be in place.

Traditional plating techniques for the detection of foodborne pathogens from insects are laborious and depend upon the competitive growth of the target bacteria in different culture media to overcome the rapid growth of the innate commensal microbiota of the insect. Most of the studies that have associated insects with bacterial pathogens have increased the sensitivity of the method by pooling together several insects rather than identifying the presence of pathogens on a per individual basis. Thus, those studies did not differentiate the body part of the insect where the pathogens were found ${ }^{13-18}$. The ability to identify whether foodborne pathogens are located on the body surface or in the alimentary 
canal of an individual insect is important as this may have epidemiological implications and may lead to different mitigation strategies. As mechanical vectors, flies that land on food for a short time may only transfer low levels of bacteria from their body surface, whereas those flies that regurgitate and defecate on the food increase the probability of transferring pathogens at potentially higher levels of infection. Consequently, it is important to estimate the prevalence of a foodborne pathogen per an individual insect and to differentiate the body part of that insect where the bacterial pathogen is located.

Even though the use of culture-independent methods to detect foodborne pathogens are increasingly being implemented, they have not been commercially used to detect foodborne pathogens from a single insect. Currently, there are validated molecular protocols that are commercially available for the rapid detection of foodborne pathogens from foods that are being used by industry and regulatory agencies. These methods include DNA-based systems for the detection of pathogens in a variety of food samples. Although molecular protocols are faster than traditional plating methods, enrichment of the sample is still required to obtain the sensitivity level of $10^{2}$ colony forming units (CFU) of the bacterial pathogen needed in polymerase chain reaction (PCR)-based methods ${ }^{19}$. Additionally, isolation of pure bacterial colonies from PCR-positive samples is needed to confirm the pathogen using appropriate methods.

The aim of this protocol is to standardize a commercially available PCR-based system used to detect pathogens from food and environmental samples for the detection of foodborne bacteria from the body surface and the alimentary canal of a single fly and to further isolate those pathogens from the samples. The sensitivity of the protocol described here was first calibrated with lab-reared adult house flies (Musca domestica) that were experimentally fed with serial dilutions of each bacterial pathogen. The standardized protocol was subsequently used to survey 100 wild-caught flies for the presence of foodborne pathogens from their body surfaces and/or alimentary canals. This standardized protocol will allow public health laboratories to detect health threats posed by insects, allowing for the possibility of collecting them as part of the environmental sampling program when performing foodborne outbreak investigations.

\section{Collection of flies}

1. Collect individual flies using sterile entomological sweep nets. Put the nets in a cooler and transfer them to the lab.

\section{Dissection of Flies}

1. Immobilize aseptically collected flies by placing them at $-20^{\circ} \mathrm{C}$ for $5-7 \mathrm{~min}$.

2. Using sterile forceps place one fly in a sterile $2 \mathrm{ml}$ tube containing $1 \mathrm{ml}$ of pre-warmed $\left(37^{\circ} \mathrm{C}\right)$ buffered peptone water (BPW). Mix the tube gently by inversion for $2 \mathrm{~min}$. It is essential that the whole body of the fly be in contact with the media so that the microbiota present on the body surface (S) of the fly will be transferred to the BPW (BPW-S). Label the tube with a number and body part of the fly (i.e., 1S).

NOTE: Please see Table of Specific Reagents/Equipment for a detailed description of materials and reagents mentioned in this protocol.

3. Using sterile forceps remove the fly from the BPW-S media and transfer it to an empty and clean 2 ml tube to surface disinfect the fly. Incubate the tube containing the BPW-S media at $37^{\circ} \mathrm{C}$ while performing the disinfection and dissection protocol.

1. Surface-disinfect the fly by immersing it in $1 \mathrm{ml}$ of $70 \%$ ethanol for $1 \mathrm{~min}$, followed by a rinse with sterile distilled water before immersing it in $1 \mathrm{ml}$ of freshly prepared $0.05 \%(\mathrm{v} / \mathrm{v})$ bleach solution. Rinse 3 times with sterile distilled water. Transfer water from the last rinse to an autoclaved $2 \mathrm{ml}$ tube.

NOTE: Discard the liquid each time by using a $1,000 \mu \mathrm{l}$ micropipette or by inverting the tube, making sure the fly remains inside the tube. Mix gently by inversion at each step of the surface-disinfection process.

2. To evaluate the effectiveness of the disinfection process, transfer $100 \mu \mathrm{l}$ of the water from the last rinse to a trypticase soy agar (TSA) plate and spread using a sterile L-shaped disposable spreader. Incubate the plate at $37^{\circ} \mathrm{C}$ for $24 \mathrm{hr}$. After incubation, register the presence of any bacterial colonies.

NOTE: The presence of bacterial colonies on the TSA plates indicates an inefficient surface-disinfection process. If this occurs, the presence of foodborne pathogens should only be reported on the body surface of the fly because cross-contamination between the body surface and the alimentary canal cannot be ruled out.

4. After surface-disinfecting the fly, transfer it to a piece of autoclaved paper towel to remove excess water and then to a sterile $60 \mathrm{~mm}$ disposable Petri dish.

5. Place the Petri dish under a dissecting scope and identify the fly to the species level using dichotomous keys for dipteran families ${ }^{20,21}$.

6. Using autoclaved fine tip forceps gently pull the anus and the whole alimentary canal $(A)$ out of the fly and aseptically transfer it to another sterile $2 \mathrm{ml}$ tube containing $1 \mathrm{ml}$ of pre-warmed $\left(37^{\circ} \mathrm{C}\right) \mathrm{BPW}$ with $0.5 \mathrm{~mm}$ zirconia/silica beads (BPW-A). Label the tube with the same number selected for the individual fly and the body part of the fly (i.e., $1 \mathrm{~A})$.

7. Mix the tube containing the BPW-A thoroughly for $5-10$ min using a cell disruptor. Incubate at $36 \pm 1{ }^{\circ} \mathrm{C}$ while performing the rest of the protocol.

8. To voucher and/or store the specimen for long-term, place the remainder of the fly in a clean $2 \mathrm{ml}$ tube and add $1-2 \mathrm{ml}$ of $95 \%$ ethanol.

\section{Primary and Secondary Enrichment}

1. Label all primary and secondary enrichment tubes containing media according to the sample number and the body part of the fly.

2. Under a sterile hood, transfer $300 \mu \mathrm{l}$ of BPW-S (surface) to sterile $2 \mathrm{ml}$ tubes containing the following media:

1. For Salmonella, use $1 \mathrm{ml}$ of pre-warmed $\left(42{ }^{\circ} \mathrm{C}\right) \mathrm{BPW}$. Incubate in a recirculating water bath at $42.5^{\circ} \mathrm{C}$ for $22-24 \mathrm{hr}$. For secondary enrichment, transfer $100 \mu \mathrm{l}$ of enriched BPW to $400 \mu \mathrm{l}$ of pre-warmed $\left(37^{\circ} \mathrm{C}\right)$ brain heart infusion (BHI) broth previously placed in sterile cluster tubes. Incubate at $37^{\circ} \mathrm{C}$ for $3 \mathrm{hr}$. 
2. For Cronobacter, use $1 \mathrm{ml}$ of pre-warmed $\left(37^{\circ} \mathrm{C}\right) \mathrm{BPW}$ with novobiocin (10 mg/L; Wallace, M., personal communication). Alternatively, use $1 \mathrm{ml}$ of the $\mathrm{R} \& \mathrm{~F}$ Enterobacter sakazakii enrichment broth with supplement (vancomycin and cefsulodin) as primary enrichment. Incubate at $37^{\circ} \mathrm{C}$ for 22 - $26 \mathrm{hr}$. For secondary enrichment, transfer $100 \mu \mathrm{l}$ of enriched BPW with novobiocin to $400 \mu \mathrm{l}$ of pre-warmed $\left(37^{\circ} \mathrm{C}\right) \mathrm{BHI}$ broth previously placed in sterile cluster tubes. Incubate at $37^{\circ} \mathrm{C}$ for $3 \mathrm{hr}$.

3. For L. monocytogenes, use $1 \mathrm{ml}$ of freshly prepared RT 24 Listeria enrichment broth (24 LEB) with selective supplement. Incubate at $37^{\circ} \mathrm{C}$ for $44 \pm 5 \mathrm{hr}$. No secondary enrichment is required for the detection of $L$. monocytogenes.

4. Repeat steps 3.2.1 - 3.2.3 above using the tube labeled as BPW-A.

\section{Preparation of the PCR-Based System for Amplification and Detection of the Target Foodborne Pathogen}

Steps 4-8 use a commercial PCR cycler/detector system, a computer workstation, and ready-to-use kits to screen for Salmonella (Salmonella 2 standard assay kit), Cronobacter species (E. sakazakii standard assay kit), and Listeria monocytogenes (L. monocytogenes 24E assay kit). Standard assays use PCR end-point detection. Each kit contains PCR-ready tablets with an intercalating dye that emits a fluorescence signal when binding to double-stranded DNA. The signal is captured during the detection phase of the PCR system program, generating a melting curve that is interpreted by the software as positive or negative.

1. Prepare reagents and equipment as specified by the manufacturer's protocol per each target foodborne pathogen. NOTE: The protocols for detecting Salmonella and Cronobacter require a one-step lysis procedure whereas the protocol for detecting $L$. monocytogenes requires a two-step lysis procedure (see sections 5 and 6 , respectively).

2. Turn on the automated heating block selecting the specific program for the target pathogen. Alternatively, if the heating blocks are manual, set temperatures to $37^{\circ} \mathrm{C}$ (for Salmonella, Cronobacter spp., and L. monocytogenes) or to $55 \pm 2{ }^{\circ} \mathrm{C}$ (for L. monocytogenes part 2 of lysis see step 6.2) and $95 \pm 3{ }^{\circ} \mathrm{C}$.

3. Make sure that the cooling blocks have been refrigerated $\mathrm{O} / \mathrm{N}$, otherwise chill them at $2-8{ }^{\circ} \mathrm{C}$ for at least $2 \mathrm{hr}$.

4. Using the computer software of the PCR-based detection system, create a rack file following manufacturer's instructions.

5. Label and arrange cluster tubes containing the lysis reagent in the rack, according to the rack file.

6. Initialize the PCR-based detection system instrument.

\section{Perform Lysis for the Detection of Salmonella and Cronobacter}

1. Prepare the lysis reagent by adding $150 \mu \mathrm{l}$ of protease to one $12 \mathrm{ml}$ bottle of lysis buffer.

2. Transfer $200 \mu \mathrm{l}$ of lysis reagent to each of the previously labeled cluster tubes. NOTE: Cluster tubes containing the lysis reagent can be stored at $2-8{ }^{\circ} \mathrm{C}$ for up to 2 weeks.

3. Using long pipette tips, transfer $20 \mu$ l of secondary enriched samples (see steps 3.2.1 and 3.2.2) to corresponding cluster tubes containing $200 \mu \mathrm{l}$ of lysis reagent. Use new pipette tips for each sample.

NOTE: Keep tubes from primary and secondary enrichment in the refrigerator (Salmonella) or at RT (Cronobacter) for further confirmation analysis of PCR-positive/ negative samples.

4. Prepare negative controls by adding $20 \mu \mathrm{l}$ of sterile BHI media to cluster tubes containing $200 \mu$ l of lysis reagent.

5. Prepare positive controls by adding $20 \mu \mathrm{l}$ of $\mathrm{O} / \mathrm{N}$ bacterial cultures (grown in $\mathrm{BHI}$ ) of any known Salmonella or Cronobacter strain to cluster tubes containing $200 \mu$ l of lysis reagent.

6. Cap cluster tubes and secure tightly using the capping tool.

7. Place the rack of cluster tubes in the automated heating block after selecting the specific program for the target pathogen. Alternatively, incubate cluster tubes at $37 \pm 2{ }^{\circ} \mathrm{C}$ for $20 \mathrm{~min}$, followed by incubation at $95 \pm 3^{\circ} \mathrm{C}$ for $10 \mathrm{~min}$. Finally, transfer the cluster tubes to cooling blocks $\left(2-8{ }^{\circ} \mathrm{C}\right)$ for $5 \mathrm{~min}$. NOTE: Cluster tubes containing the lysate can be stored at $-20^{\circ} \mathrm{C}$ for up to 2 weeks.

\section{Perform Lysis for the Detection of $L$. monocytogenes}

1. Perform part one of lysis as follows:

1. Add $1.8 \mathrm{ml}$ of sterile deionized water to the bottle of fully thawed lysing agent 1. NOTE: Store lysing agent 1 at $2-8^{\circ} \mathrm{C}$ until ready to use. After opening and diluting, store at RT $\left(20-30{ }^{\circ} \mathrm{C}\right)$ for up to 6 months.

2. Combine lysing agents 1 and 2 in a $4: 1$ ratio $(40 \mu$ l of diluted lysing agent 1 and $10 \mu$ l of lysing agent 2 per each sample). Transfer $50 \mu l$ of the combined lysing agents to cluster tubes. Use the mixture within $4 \mathrm{hr}$.

3. Add $500 \mu$ l of primary enriched sample (see step 3.2.3) to the cluster tube containing the $50 \mu$ of the combined lysing agents.

4. Prepare a negative control by adding $500 \mu \mathrm{l}$ of sterile 24 LEB to $50 \mu \mathrm{l}$ of the combined lysing agents.

5. Prepare a positive control by adding $500 \mu \mathrm{l}$ of O/N L. monocytogenes culture grown in $24 \mathrm{LEB}$ to $50 \mu \mathrm{l}$ of the combined lysing agents.

6. Cap the cluster tubes, mix gently and place in heating block at $37 \pm 1{ }^{\circ} \mathrm{C}$ for $30 \mathrm{~min}$. NOTE: Keep tubes from primary enrichment in the refrigerator for further confirmation analysis of PCR-positive/negative samples.

2. Perform part 2 of lysis as follows:

1. Prepare the lysis reagent as instructed in steps 5.1 and 5.2 .

2. Using long pipette tips transfer $20 \mu \mathrm{l}$ of part one lysate to cluster tubes containing $200 \mu \mathrm{l}$ of lysis reagent. Use new pipette tips for each sample.

3. Cap cluster tubes and secure tightly using the capping tool.

4. Place cluster tubes in automated heating block selecting the specific program for $L$. monocytogenes. Alternatively, incubate cluster tubes at $55 \pm 2{ }^{\circ} \mathrm{C}$ for $30 \mathrm{~min}$, followed by incubation at $95 \pm 3{ }^{\circ} \mathrm{C}$ for $10 \mathrm{~min}$. Finally, transfer the cluster tubes to cooling blocks $(2-8$ $\left.{ }^{\circ} \mathrm{C}\right)$ for $5 \mathrm{~min}$. 
NOTE: Cluster tubes containing the lysate can be stored at $-20^{\circ} \mathrm{C}$ for up to 2 weeks.

\section{Hydrate PCR-Ready Tablets}

1. Select a chilled $\left(4^{\circ} \mathrm{C}\right)$ PCR cooling block and place a PCR tube rack over the insert.

2. Place corresponding PCR tubes containing the PCR-ready tablets (included with each kit) for the target foodborne pathogen in the holder, according to the rack file.

3. Using the decapping tool, carefully remove the caps from PCR-tubes. Discard the caps and verify that each tube contains a tablet.

4. Transfer $50 \mu \mathrm{l}$ (for Salmonella and Cronobacter) or $30 \mu \mathrm{l}$ (for L. monocytogenes) of lysate to specific PCR tubes. Use new optical caps and secure tightly onto the PCR tubes using the capping tool. NOTE: After adding the lysate to PCR-ready tablets, samples must remain chilled at $2-8{ }^{\circ} \mathrm{C}$ until loaded into the PCR-based detection system. The PCR tubes can be centrifuged at $2,500 \mathrm{xg}$ for a few seconds to assure that the full volume is in the bottom the tube.

5. Load the PCR tubes into the PCR cycler/detection system instrument by opening the instrument drawer.

6. Place the rack of PCR tubes into the wells in the drawer and check that the tubes are seated correctly.

7. Close the drawer and initiate the program as described by the manufacturer's protocol. NOTE: The PCR-based instrument has preset cycling parameters for each foodborne pathogen.

8. Verify that the PCR cycling status bar displays a blue bar indicating that the amplification portion of the program is running. NOTE: For standard PCR assays, the processing time of the full program (amplification and detection) takes approximately 3 - 3.5 hr to complete.

\section{Review Results}

1. After processing is complete, follow the screen prompts from the PCR-based system instrument to remove samples and review results.

2. If the target foodborne pathogen is present in the sample (either the surface or the alimentary canal of the fly) the well is red with a 'plus' sign (positive). If the pathogen is absent, the well is green with a 'minus' sign (negative).

3. If the well is yellow with a red bar across the center, it indicates a signal error.

\section{Isolation of Bacterial Pathogens from PCR-Positive Results}

1. Select tubes from the primary (for L. monocytogenes) or secondary (for Salmonella and Cronobacter) enrichment of those samples that were PCR-positive. Also, randomly select $3-5 \%$ of samples that were PCR-negative and proceed as follows:

2. For Salmonella:

1. Add $100 \mu \mathrm{l}$ of the secondary enrichment media to $10 \mathrm{ml}$ of Rappaport-Vassiliadis (RV) medium and to $1 \mathrm{ml}$ of tetrathionate (TT) broth. Incubate tubes at $42.5^{\circ} \mathrm{C}$ in a recirculating water bath for 22 - $24 \mathrm{hr}$.

2. After incubation, streak a $3 \mathrm{~mm}$ loopful $(10 \mu \mathrm{l})$ of each, RV and TT media on bismuth sulfite (BS) agar, xylose lysine desoxycholate (XLD) agar, and Hektoen enteric (HE) agar. Incubate plates at $35 \pm 1{ }^{\circ} \mathrm{C}$ for $22-24 \mathrm{hr}$.

3. After incubation, examine plates for the presence of typical Salmonella colonies on each media. If no isolated colonies can be obtained after several sub-culturing steps, consider the sample as negative and report as a false positive for the PCR-based system. NOTE: For typical Salmonella colonies on specific media see ${ }^{22}$. Select five presumptive typical Salmonella colonies and subculture them on BS, XLD, or HE until pure cultures of isolated/single colonies are obtained.

4. Select one pure colony and identify presumptive Salmonella by using biochemical commercial tests such as the VITEK 2 identification card or API biochemical identification system, following the manufacturer's instructions.

3. For Cronobacter:

1. Streak a $3 \mathrm{~mm}$ loopful $(10 \mu \mathrm{l})$ of the secondary enrichment media on two plates of chromogenic culture media such as R\&F Enterobacter sakazakii (Cronobacter) chromogenic plating medium, and/or ChromID Sakazakii Agar. Incubate plates at $35^{\circ} \mathrm{C}$ for 22 $24 \mathrm{hr}$.

2. After incubation, examine plates for the presence of typical Cronobacter colonies (blue-black to blue-gray). Select 5 presumptive Cronobacter colonies and subculture them onto R\&F Enterobacter sakazakii (Cronobacter) chromogenic plating medium, ChromID Sakazakii Agar, or TSA until pure cultures of isolated/single colonies are obtained.

NOTE: If no isolated colonies can be obtained after several sub-culturing steps, consider the sample as negative and report as a false positive for the PCR-based detection system.

3. Select one pure colony and identify presumptive Cronobacter by using biochemical commercial tests such as the VITEK 2 identification card or API 20E biochemical identification system, following the manufacturer's instructions.

4. For L. monocytogenes:

1. Streak a $3 \mathrm{~mm}$ loopful $(10 \mu \mathrm{l})$ of the primary enrichment media on two plates of Brilliance Listeria agar (BLA). Incubate plates at $36 \pm 1$ ${ }^{\circ} \mathrm{C}$ for 22 - $26 \mathrm{hr}$.

2. After incubation, examine plates for the presence of presumptive $L$. monocytogenes (blue-green) colonies. Select 5 presumptive $L$. monocytogenes colonies and subculture them on BLA until obtaining pure cultures of isolated/single colonies. Re-incubate negative plates at $36 \pm 1{ }^{\circ} \mathrm{C}$ for an additional $22-26 \mathrm{hr}$.

3. Select one pure colony and identify presumptive L. monocytogenes by using commercial biochemical tests such as the VITEK 2 identification card or API Listeria biochemical identification system, following the manufacturer's instructions.

5. Presumptive foodborne pathogens isolated from insects should be further confirmed and serotyped in a reference laboratory. 


\section{Representative Results}

This protocol was first calibrated on a set of lab-reared house flies that were experimentally fed for $24 \mathrm{hr}$ with liquid fly food ( $2 \%$ powder milk) containing serial dilutions $\left(10^{2}-10^{8} \mathrm{CFU} / \mathrm{ml}\right)$ of $C$. sakazakii, S. enterica, L. monocytogenes, or $C$. jejuni $(\mathrm{n}=21$ for each bacterial pathogen). Enrichment media as well as incubation times and temperatures were adjusted for each foodborne pathogen until the PCR-based system was able to detect the lowest levels of bacteria $\left(10^{2} \mathrm{CFU} / \mathrm{ml}\right)$ from the body surface and the alimentary canal of a single experimentally fed fly. Using the enrichment media and conditions described in the protocol section, the PCR-based system detected C. sakazakii, S. enterica, and L. monocytogenes from the body surface of $100 \%$ of flies fed with bacterial inocula $>10^{3} \mathrm{CFU} / \mathrm{ml}$ (Figure 1A). When flies were fed with $10^{2}$ CFU $/ \mathrm{ml}$, the percentage of detection of C. sakazakii, S. enterica, and L. monocytogenes from their body surface was $100 \%, 66 \%$, and $33 \%$, respectively (Figure 1A). The PCR-based system also detected these three foodborne pathogens from the alimentary canal of flies fed with all bacterial concentrations at percentages $\geq 33 \%$ (Figure 1B). However, the detection of $C$. jejuni was only achieved when lab-reared flies were experimentally fed with liquid food containing the highest bacterial inoculum $\left(10^{8} \mathrm{CFU} / \mathrm{ml}\right)$. Hence, $C$. jejuni was excluded from the group of foodborne pathogens that could be tested from individual synanthropic filth flies using this PCR-based detection system.

With this standardized protocol, we were able to determine the prevalence of Cronobacter spp., S. enterica, and L. monocytogenes from the body surface and/or the alimentary canal of 100 wild flies that were individually and aseptically caught from the dumpster area of ten urban restaurants located in the metropolitan area of Washington, D.C. ${ }^{5}$ Collected filth flies were representative of at least six species including M. domestica (47\%), Lucilia cuprina (33\%), L. sericata (14\%), Cochliomyia macellaria (2\%), Sarcophaga haemorrhoidalis (2\%), and Ophyra leucostoma (1\%). One fly was identified only to family level (Anthomyiidae; $1 \%$ ). The surface-disinfection protocol was effective at avoiding cross-contamination between the body parts of the fly because no bacterial growth was observed on TSA plates for water from the last disinfection rinse of each individual fly. Thus, a distinction could be made between foodborne bacteria present on the body parts of each fly.

No false positives were detected from samples of the body surface and the alimentary canal of individual flies when using this commercial PCRbased system for the detection of $S$. enterica and $L$. monocytogenes, and the confirmation of viable pathogens on agar plates was in agreement with PCR-positive results. However, it was not possible to isolate pure cultures of Cronobacter spp. from all PCR-positive samples. Hence, the detection of this pathogen by the PCR-based system showed false positives from the body surface $(50 \%$; $9 / 18)$ and the alimentary canal $(48 \%$; 16/33) of single wild-caught flies. Randomly selected PCR-negative samples that were plated on specific media, confirmed the absence of the foodborne pathogens. Therefore, no false negatives were detected from any of the samples when using this commercial PCR-based system to detect Cronobacter spp., S. enterica, or L. monocytogenes.

Only those PCR-positive samples where the pathogen was isolated and confirmed were considered positive and included for statistical analysis. The overall presence of foodborne pathogens in the alimentary canal of wild-caught filth flies was significantly higher than on the body surface $\left(x^{2}=6.8772, \mathrm{df}=1, p=0.0087\right) .22 \%$ of the alimentary canals and $8 \%$ of the body surfaces of collected wild flies were positive for at least one of the three foodborne pathogens (Figure 2). Overall, the prevalence of Cronobacter spp. on either the body surfaces or alimentary canals of collected flies was statistically higher (19\%; Fisher's exact test $p=0.0165)$ than the prevalence of S. enterica $(7 \%)$ and L.monocytogenes $(4 \%)$. However, no statistical differences were observed when performing pairwise comparisons between the body parts of the flies for each bacterial pathogen (Figure 3; Fisher's exact test $p=0.1464, p=0.1184$, and $p=0.6212$ for Cronobacter spp., S. enterica, and L.monocytogenes, respectively). None of the flies were positive for all three pathogens evaluated. However, three of the flies (two $L$. cuprina and one $L$. sericata) carried Salmonella spp. and $L$. monocytogenes on the surface or in the alimentary canal. 

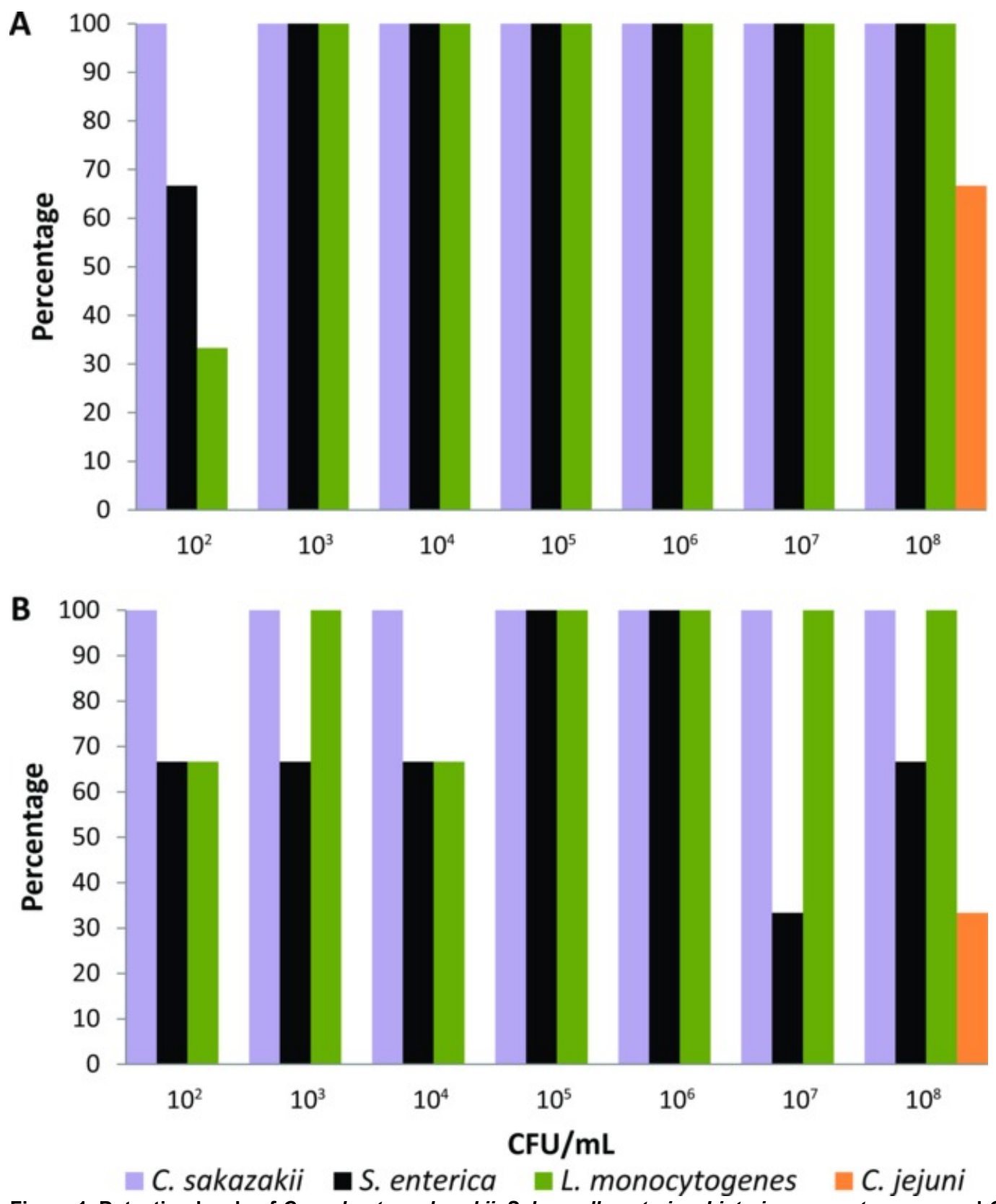

Figure 1. Detection levels of Cronobacter sakazakii, Salmonella enterica, Listeria monocytogenes, and Campylobacter jejuni from (A) the body surface and $(B)$ the alimentary canal of individual lab-reared house flies fed with liquid food containing different bacterial inocula $(n=21$ for each bacterial pathogen, $n=3$ per each bacterial concentration). Please click here to view a larger version of this figure. 


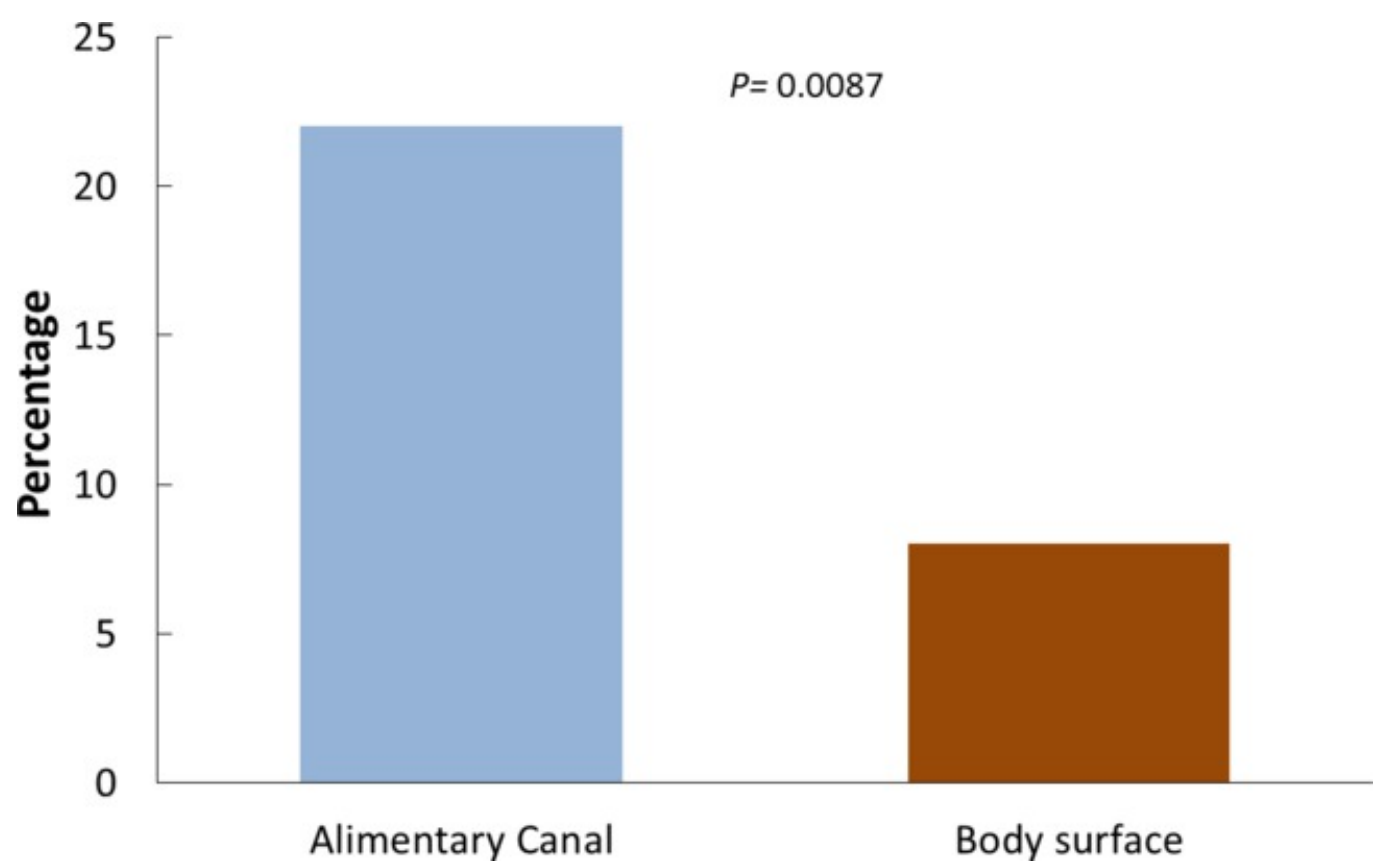

Figure 2. Percentage of body surfaces and alimentary canals of individual flies found positive for any of the target foodborne pathogens.

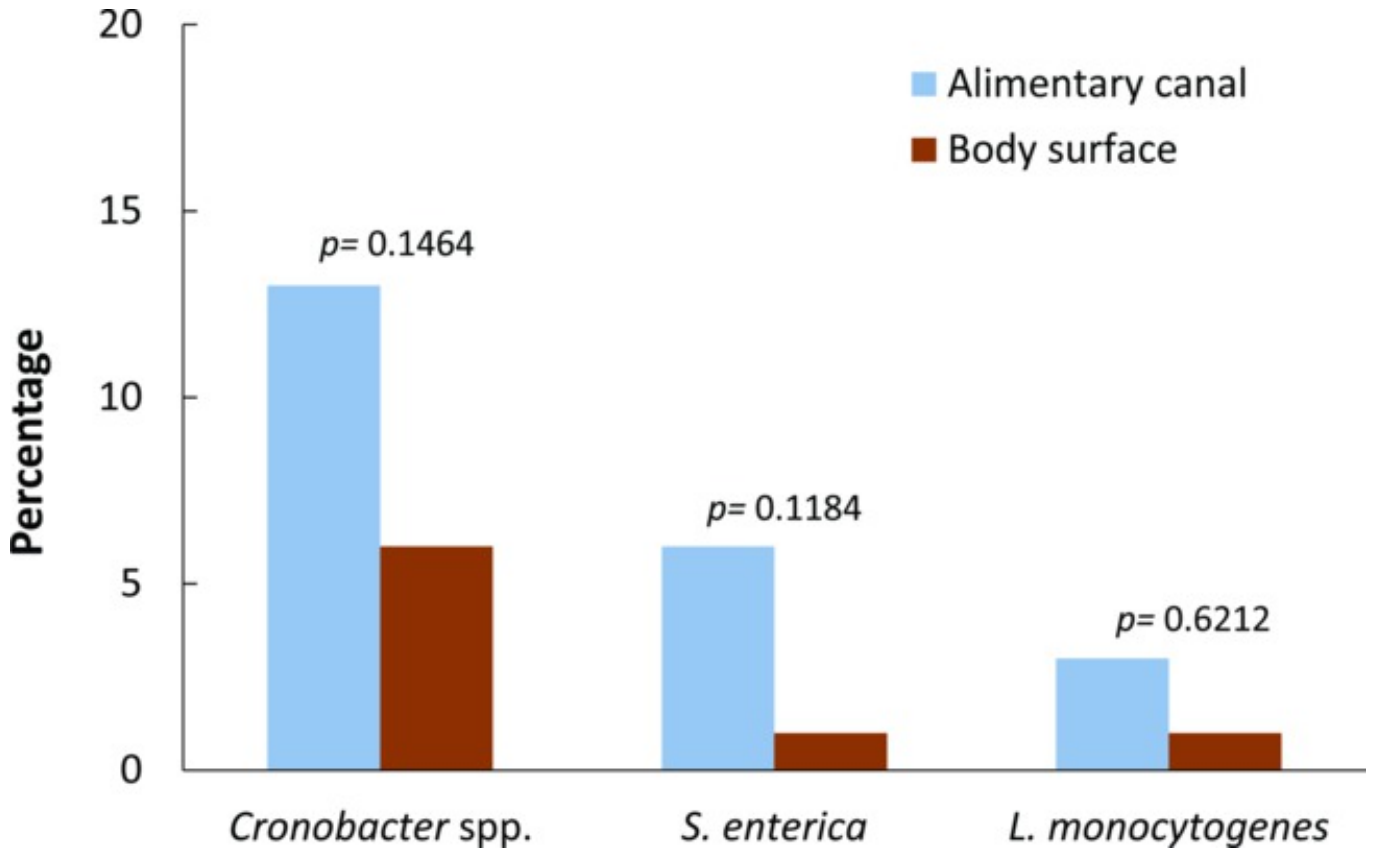

Figure 3. Prevalence of Cronobacter spp., Salmonella enterica, and Listeria monocytogenes from the body surface and the alimentary canal of synanthropic wild-caught flies. The $p$ values reported are from pairwise comparisons between the body surface and the alimentary canal for each bacterial pathogen (Fisher's exact test, $p$ value $<0.05$ indicates statistical significance). Copyright $\odot$ American Society for Microbiology, Journal of Applied and Environmental Microbiology 78 (22):7891-902, 2012. doi: 10.1128/AEM.02195-12.

\section{Discussion}

Previous studies that have detected foodborne pathogens from wild insects have used a great variety of protocols that might not include the necessary information to accurately assess the food-related risk of the presence of a single fly in foods or food-related environments ${ }^{13,15,23,24}$. Here, we demonstrated that using this standardized protocol, it is possible to detect and isolate Cronobacter spp., $S$. enterica, and $L$. monocytogenes from the body surface and the alimentary canal of single flies caught in the wild. Because insects may carry low numbers of the target foodborne pathogen and high numbers of other indigenous microbiota ${ }^{25,26}$, this protocol requires primary (and sometimes secondary) enrichment of the samples in specific culture media to increase the sensitivity of detection of the target foodborne pathogen. Results from the PCR-based detection system were obtained within approximately $30 \mathrm{hr}$ (for the detection of Cronobacter spp. and S. enterica) and $48 \mathrm{hr}$ (for 
the detection of $L$. monocytogenes) after initially processing the samples. Thus, this protocol is reliable as well as rapid and sensitive enough to screen a single fly for the presence of foodborne pathogens.

Confirmation of PCR-positive results and isolation of viable bacteria is part of the standard operating procedure of many laboratories. In addition, for epidemiology purposes, pure bacterial cultures from PCR-positive samples are required to further confirm and serotype the foodborne pathogen using biochemical, immunological, or genetic methods. Although no false positives were observed when detecting $S$. enterica and $L$. monocytogenes from the body parts of single wild-caught flies, using this protocol, we found up to a $50 \%$ rate of false positives for Cronobacter spp. This suggests that the PCR-based detection system for the genus Cronobacter may cross-react with other Enterobacteriaceae present among the highly complex microbiota carried by flies. Thus, isolation and purification of pure colonies of the genus Cronobacter from PCRpositive samples require more selective plating than the other pathogens evaluated.

This protocol has primarily been standardized to screen individual wild-caught flies for the presence of Cronobacter spp., $S$. enterica, and $L$. monocytogenes using a commercial PCR-based detection system. However, this protocol was also easily adapted to screen body parts of single flies for the presence of other foodborne pathogens such as enterohemorrhagic E. coli O157:H7 (using either the E. coli O157:H7 MP standard assay kit or the E. coli O157:H7 real-time assay kit) and the shiga-toxigenic E. coli (STEC) group (using the real-time STEC suite), obtaining sensitivities $>80 \%$ (unpublished data). Also, this protocol can potentially be adapted to detect foodborne pathogens from other insects that are known vectors of diseases (cockroaches and ants), but more research in this area is needed.

Foodborne illness outbreak investigations are very dynamic and comprise a multi-step process that may vary according to the specific situation and the local environment being investigated ${ }^{12,27}$. These investigations are important because they provide immediate public health protection by preventing future illnesses. Additionally, these investigations can elucidate new mechanisms by which foodborne microorganisms are spread, and raise important questions that lead to new areas for research ${ }^{28}$. Investigative techniques as well as standardized, rapid, and sensitive protocols are necessary for detecting foodborne pathogens from individual insects. This standardized protocol opens the opportunity to aseptically collect insects like flies, which can vector the foodborne bacterial pathogen, as part of an environmental sampling program. The epidemiological information that can be gained from this would be of use in constructing an accurate picture of the mechanisms of transmission of foodborne pathogens by insects (i.e., length of exposure time: a fly by landing versus flies landing, defecating, and regurgitating).

Finally, even though the commercial PCR-based detection system described here is practical to use and simplifies PCR amplification and visualization of a genus-level amplicon, it is by no means the only appropriate system. The lysate from enriched samples could alternatively be used to screen for the presence of foodborne pathogens by using publically available species-specific primer pairs. However, detection sensitivity should be demonstrated prior to their use.

\section{Disclosures}

The use of specified instrumentation is not an endorsement by the U.S. Food and Drug Administration. The authors certify that there is no conflict of interest with any financial organization regarding the material discussed in this article.

\section{Acknowledgements}

Thanks to Ben D. Tall, Yi Chen, and Thomas Hammak from the U.S. Food and Drug Administration (FDA), Center for Food Safety and Applied Nutrition (CFSAN) for critically reviewing the manuscript. The authors also thank Hannah Lee (research internship program, Joint Institute for Food Safety and Applied Nutrition (JIFSAN), University of Maryland) for laboratory assistance and David Weingaertner (FDA, CFSAN) for preparing the figure of the schematic overview shown in the video.

\section{References}

1. Zurek, L., Gorham, J. R. Wiley Handbook of Science and Technology for Homeland Security. Voeller, J. G. 1-16 Wiley Inc (2008).

2. Olsen, A. R., Gecan, J. S., Ziobro, G. C., Bryce, J. R. Regulatory action criteria for filth and other extraneous materials V. Strategy for evaluating hazardous and nonhazardous filth. Regulatory Toxicology and Pharmacology. 33, (3), 363-392 (2001).

3. Hald, B., Skovgård, H., Pedersen, K., Bunkenborg, H. Influxed insects as vectors for Campylobacter jejuni and Campylobacter coli in Danish broiler houses. Poultry Science. 87, (7), 1428-1434 (2008).

4. Kobayashi, M., et al. Houseflies: Not simple mechanical vectors of enterohemorrhagic Escherichia coli O157:H7. American Journal of Tropical Medicine and Hygiene. 61, (4), 625-629 (1999).

5. Pava-Ripoll, M., Pearson, R. E. G., Miller, A. K., Ziobro, G. C. Prevalence and relative risk of Cronobacter spp., Salmonella spp., and Listeria monocytogenes associated with the body surfaces and guts of individual filth flies. Applied and Environmental Microbiology. 78, (22), 7891-7902 (2012).

6. Hewitt, C. G. Houseflies and how they spread disease. Cambridge University Press (1912)

7. Rochon, K., Lysyk, T. J., Selinger, L. B. Retention of Escherichia coli by house fly and stable fly (Diptera:Muscidae) during pupal metamorphosis and eclosion. Journal of Medical Entomology. 42, (3), 397-403 (2005).

8. Greenberg, B., Kowalski, J. A., Klowden, M. J. Factors affecting the transmission of Salmonella by flies: natural resistance to colonization and bacterial interference. Infection and Immunity. 2, (6), 800-809 (1970).

9. Mramba, F., Broce, A. B., Zurek, L. Vector competence of stable flies, Stomoxys calcitrans L. (Diptera:Muscidae), for Enterobacter sakazakii. Journal of Vector Ecology. 32, (1), 134-139 (2007).

10. Ekdahl, K., Normann, B., Andersson, Y. Could flies explain the elusive epidemiology of campylobacteriosis. Bmc Infectious Diseases. 5, (11), $11(2005)$

11. Nayduch, D., Noblet, G. P., Stutzenberger, F. J. Vector potential of houseflies for the bacterium Aeromonas caviae. Medical and Veterinary Entomology. 16, (2), 193-198 (2002). 
12. Multistate and Nationwide Foodborne Outbreak Investigations: A Step-by-Step Guide. CDC Atlanta, GA Available from: http://www.cdc.gov/ foodsafety/outbreaks/investigating-outbreaks/investigations/index.html (2013).

13. Sievert, K., Messler, S., Klimpel, S., Feffer, K. Comprehensive study on the occurrence and distribution of pathogenic microorganisms carried by synanthropic flies caught at different rural locations in Germany. Journal of Medical Entomology. 46, (5), 1164-1166 (2009).

14. Hernández-Escareño, J. J., et al. Presence of Enterobacteriaceae, Listeria spp., Vibrio spp. and Staphylococcus spp. in house fly (Musca domestica L.), collected and macerated from different sites in contact with a few animals species. Revista Cientifica-Facultad De Ciencias Veterinarias. 22, (2), 128-134 (2012).

15. Mian, L. S., Maag, H., Tacal, J. V. Isolation of Salmonella from muscoid flies at commercial animal establishments in San Bernardino county, California. Journal of Vector Ecology. 27, (1), 82-85 (2002).

16. Olsen, A. R., Hammack, T. S. Isolation of Salmonella spp. from the housefly, Musca domestica L., and the dump fly, Hydrotaea aenescens (Wiedemann) (Diptera:Muscidae), at caged-layer houses. Journal of Food Protection. 63, (7), 958-960 (2000).

17. Holt, P. S., Geden, C. J., Moore, R. W., Gast, R. K. Isolation of Salmonella enterica serovar Enteritidis from houseflies (Musca domestica) found in rooms containing Salmonella serovar Enteritidis-challenged hens. Applied and Environmental Microbiology. 73, (19), 6030-6035 (2007).

18. Mramba, F., Broce, A., Zurek, L. Isolation of Enterobacter sakazakii from stable flies, Stomoxys calcitrans L. (Diptera:Muscidae). Journal of Food Protection. 69, (3), 671-673 (2006).

19. Koyuncu, S., Andersson, M. G., Haggblom, P. Accuracy and Sensitivity of Commercial PCR-Based Methods for Detection of Salmonella enterica in Feed. Applied and Environmental Microbiology. 76, (9), 2815-2822 (2010).

20. Gagné, R. Insect and mite pests in food, an illustrated key. Gorham, J. R. 1, 269-296 U.S. Department of Agriculture and U.S. Department of Health and Human Service (1991).

21. Greenberg, B. Flies and disease, Vol I. Ecology, classification and biotic associations. Princeton University Press (1971).

22. Wallace, H. A., Jacobson, A., Hammack, T. S. Chapter 5 Salmonella. Bacteriological Analytical Manual. http://www.fda.gov/downloads/Food/ FoodScienceResearch/UCM244774.pdf (2007).

23. Barro, N., Aly, S., Tidiane, O. C. A., Sababenedjo, T. A. Carriage of bacteria by proboscises, legs, and feces of two species of flies in street food vending sites in Ouagadougou, Burkina Faso. Journal of Food Protection. 69, (8), 2007-2010 (2006).

24. Ugbogu, O. C., Nwachukwu, N. C., Ogbuagu, U. N. Isolation of Salmonella and Shigella species from house flies (Musca domestica L.) in Uturu, Nigeria. African Journal of Biotechnology. 5, (11), 1090-1091 (2006).

25. Brownlie, J. C., Johnson, K. N. Symbiont-mediated protection in insect hosts. Trends in Microbiology. 17, (8), $348-354$ (2009).

26. Feldhaar, H. Bacterial symbionts as mediators of ecologically important traits of insect hosts. Ecological Entomology. 36, (5), 533-543 (2011).

27. Foodborne disease outbreaks: Guidelines for investigation and control. World Health Organization http://www.who.int/foodsafety/publications/ foodborne_disease/outbreak_guidelines.pdf (2008).

28. Wright, A. P., Gould, L. H., Mahon, B., Sotir, M. J., Tauxe, R. V. Overview of the Impact of Epidemic-Assistance Investigations of Foodborne and Other Enteric Disease Outbreaks, 1946-2005. American Journal of Epidemiology. 174, S23-S35 (2011). 